\title{
Combustion and Mechanical Properties of Polymer-Modified Cement Mortar at High Temperature
}

\author{
Hyung-Jun Kim ${ }^{1}$ and Won-Jun Park ${ }^{2}$ \\ ${ }^{1}$ Hazard Mitigation Evaluation Technology Center, Korea Conformity Laboratories, Cheongju 28115, Republic of Korea \\ ${ }^{2}$ Department of Building System Engineering, Kangwon National University, Samcheok 25913, Republic of Korea \\ Correspondence should be addressed to Won-Jun Park; wjpark@kangwon.ac.kr
}

Received 22 March 2017; Accepted 7 June 2017; Published 11 July 2017

Academic Editor: Michele Zappalorto

Copyright (c 2017 Hyung-Jun Kim and Won-Jun Park. This is an open access article distributed under the Creative Commons Attribution License, which permits unrestricted use, distribution, and reproduction in any medium, provided the original work is properly cited.

\begin{abstract}
Although polymer-modified cement mortar (PCM) has been extensively used as finishing and repairing material, it is necessary to understand its combustion properties and mechanical properties at high temperature. This study evaluated the combustion characteristics with varying experimental parameters such as polymer type, unit polymer content, polymer-cement ratio, and thickness of the specimen. This study also evaluated the compressive strength and elastic modulus of PCMs with focus on the effects of the type of polymer, unit polymer content, and polymer-cement ratio. As a result, the incombustibility of the PCM was in the following order: SBR $<$ VVA $<$ EVA. After heating end, the mass loss rate of the PCM was less than 30\%, regardless of the polymer type, unit polymer content, and W/C. In heat release rate test, the higher the unit polymer content, the greater the total heat release, regardless of the difference in W/C. The PAE series showed excellent fire resistance in the temperature range of $200 \sim 400^{\circ} \mathrm{C}$. PCMs with a unit polymer content of $5 \%$, modified with EVA and PAE, showed outstanding compressive strength at $200 \sim 400^{\circ} \mathrm{C}$. At elevated temperature, the modulus of elasticity of PCM declined with an increase in the unit polymer content, regardless of the polymer type.
\end{abstract}

\section{Introduction}

Repair and strengthening are necessary to extend the service life of existing buildings. Polymer-modified cement mortar (PCM) has been extensively used for repairing works because PCM has superior performances as a high-performance material, particularly for finishing and repairing works in concrete buildings [1-4]. PCMs are also commonly used in civil infrastructures, bridges, external wall insulation mortar, self-leveling mortar, and concrete repaired fields due to their excellent strength, environmental protection, adhesion, waterproofing, resistance to chemical attack, and workability [5-8]. Additionally, PCM has outstanding performance compared to ordinary mortar as concrete repair materials in case of applying them to deteriorated reinforced concrete structure [9-12]. However, it is very difficult to choose the appropriate patch repair materials due to insufficient experimental data on the fire resistance and safety of the
PCM [12, 13]. With the increasingly widespread use of PCM in buildings, concern has developed regarding the behavior of this material in the case of fire because PCM is generally combustible and susceptible to deterioration of the mechanical and bonding properties at elevated temperature [12-14]. Therefore, it is necessary to clarify its behavior at high temperature upon exposure to fire; however, insufficient data are available in this regard [14-16]. To meet fire endurance requirements, the performance of these materials at elevated temperature must be understood based on assessment to the mechanical properties [14]. However, when repair is required, it is very difficult to select the appropriate patch repair materials because of insufficient experimental data on the fire resistance and safety of PCM [7-9].

As PCM contains an organic polymer, it is necessary to understand its combustion properties and mechanical properties at high temperature such as those encountered during fires, for which there is not sufficient available data. 
TABLE 1: Physical properties of polymers.

\begin{tabular}{lcccc}
\hline $\begin{array}{l}\text { Type of } \\
\text { polymer }\end{array}$ & $\begin{array}{c}\text { Volatile } \\
\text { portion }(\%)\end{array}$ & $\begin{array}{c}\text { Particle } \\
\text { diameter* } \\
(\%)\end{array}$ & $\begin{array}{c}\text { Acid value } \\
(\mathrm{mgKOH} / \mathrm{mg})\end{array}$ & $\begin{array}{c}\text { Apparent } \\
\text { density } \\
(\mathrm{g} / \mathrm{mL})\end{array}$ \\
\hline EVA & Less than 2.0 & Less than 2.0 & Less than 2.0 & $0.50 \pm 0.10$ \\
VVA & Less than 2.0 & Less than 2.0 & Less than 2.0 & $0.53 \pm 0.10$ \\
PAE & Less than 2.0 & Less than 2.0 & Less than 2.0 & $0.50 \pm 0.10$ \\
\hline $\begin{array}{l}\text { Polymer } \\
\text { dispersion }\end{array}$ & $\begin{array}{c}\text { Solid ratio } \\
(\%)\end{array}$ & $\begin{array}{c}\mathrm{pH} \\
\left(20^{\circ} \mathrm{C}\right)\end{array}$ & $\begin{array}{c}\text { Viscosity } \\
(\mathrm{mPa} \cdot \mathrm{s})\end{array}$ & Density \\
$(\mathrm{g} / \mathrm{mL})$
\end{tabular}

${ }^{*}$ Residual mass ratio after passing through a $300 \mu \mathrm{m}$ sieve.

Conventional technologies and existing studies are mainly focusing on the mechanical properties such as adhesion and compressive strength, mix proportions of PCM, and durability for use before repairing and after repairing using PCMs in concrete structure.

This study evaluated the combustion characteristics of PCM by means of cone calorimeter, noncombustibility, and flammability tests with varying experimental parameters such as polymer type, unit polymer content, polymer-cement ratio, and thickness of the specimen. The effects of polymer type, unit polymer content, and water-cement ratio (W/C) were evaluated from the results of the above-mentioned tests. In addition, ignition and heat release rate tests were performed for various PCM thicknesses. Additionally, the mechanical properties of PCM are evaluated through the hot pressing test. The effect of the types of polymer and the unit polymer content are evaluated by analyzing the compressive strength and modulus of elasticity.

\section{Experimental Procedure}

This study evaluated the combustion characteristics of PCMs by means of cone calorimeter, noncombustibility, and flammability tests with varying experimental parameters such as polymer type, unit polymer content, polymer-cement ratio, and thickness of the specimen $[15,16]$. This study also evaluated the compressive strength and elastic modulus of PCMs containing four types of polymers (ethylenevinyl acetate copolymer (EVA), vinyl acetate-vinyl versatate (VVA), styrene butadiene rubber (SBR), and polyacrylic ester (PAE)) with focus on the effects of the type of polymer, unit polymer content, and polymer-cement ratio.

\subsection{Combustion Properties of PCM}

2.1.1. Materials and Composition. Portland cement and fine aggregate (fineness modulus 2.97, density $2.63 \mathrm{~g} / \mathrm{cm}^{3}$, and water absorption $1.81 \%$ ) were used to produce the mortar. Polymers specified in JIS A 6203 (polymer dispersions and redispersible polymer powders for cement modifiers), EVA, VVA, PAE, and SBR were used for cement modifiers. Meanwhile, $1 \%$ of a blowing agent was added to the redispersible polymer powders. $1 \%$ of the blowing agent was added to the polymer dispersion at different total solid ratios. Sixty compositions were used for the tests, with a fixed cementfine aggregate (mass ratio of $1: 3$ ) and various polymer types, polymer amounts, and $\mathrm{W} / \mathrm{C}$ values. In this study, the amount of the polymer is expressed as weight per unit volume. For example, $10 \mathrm{~kg} / \mathrm{m}^{3}$ of the unit polymer weight in the PCM composition corresponds to $2 \%$ polymer-cement ratio. Flat specimens $(100 \times 100 \times 10(\mathrm{~mm}))$ were used for the heat release rate tests and cylindrical specimens (diameter $44 \times$ $50(\mathrm{~mm}))$ were used for the noncombustibility tests. The 100 $\times 100 \times 400(\mathrm{~mm})$ specimen used for the ignition test was cut into three types of test pieces, $100 \times 100 \times 10(\mathrm{~mm})$, $100 \times 100 \times 30(\mathrm{~mm})$, and $100 \times 100 \times 50(\mathrm{~mm})$, after water curing $\left(20^{\circ} \mathrm{C}\right)$ for four weeks. The physical properties of the polymers used are presented in Table 1. Table 2 shows the PCM composition and experimental parameters. All the specimens were cured for four weeks in water at $20^{\circ} \mathrm{C}$ and then subjected to air curing at $20^{\circ} \mathrm{C}$ and $60 \% \mathrm{RH}$ for nine weeks. Finally, the samples were dried at $60^{\circ} \mathrm{C}$ and cooled to room temperature in a desiccator for three days before testing. Two specimens with $0.5 \%-2.0 \%$ water absorption were subjected to the heat release rate and ignition tests. Three specimens with $2.0 \%-4.0 \%$ water absorption were subjected to the noncombustibility test.

2.1.2. Test Methods. The heat release rate test was conducted according to ISO 5660-1 (Cone Calorimeter Standard Test Method) [17]. The source of ignition was an electric spark generated by a cone-type electric. The heat release amount and heat release rate were measured by oxygen-consumption calorimetry [15-17]. An incombustible material shows a total calorific value of less than $8 \mathrm{MJ} / \mathrm{m}^{2}$ for $20 \mathrm{~min}$ after heating and a maximum heat release rate of less than $200 \mathrm{~kW} / \mathrm{m}^{2}$ for $10 \mathrm{~s}$ continuously. In addition, such a material is devoid of cracks or holes on the surface, which render it hazardous when used as a fire retardant. Noncombustibility tests were conducted according to ISO 1182 (reaction to fire tests for building products: noncombustibility test) [18]. The temperature of the heating furnace and weight change of the specimen were measured. As part of the test procedure, a cylindrical specimen was placed in a heating furnace at $750^{\circ} \mathrm{C}$, and the temperature increase inside the furnace was measured.

As an important requirement in the noncombustibility test, the difference between the temperature of the incombustible material and the maximum temperature inside the 
TABLE 2: PCM composition.

\begin{tabular}{|c|c|c|c|c|c|c|}
\hline \multirow{3}{*}{ Type of polymer } & \multirow{3}{*}{$\begin{array}{l}\text { Polymer content } \\
\qquad\left(\mathrm{kg} / \mathrm{m}^{3}\right)\end{array}$} & \multicolumn{5}{|c|}{ Mortar flow (mm) } \\
\hline & & $\mathrm{W} / \mathrm{C}$ & & W/C 50\% & & $\mathrm{W} / \mathrm{C}$ \\
\hline & & $45 \%$ & $10(\mathrm{~mm})$ & $30(\mathrm{~mm})$ & $50(\mathrm{~mm})$ & $60 \%$ \\
\hline None $^{*}$ & 0 & 113 & 150 & 159 & 159 & 195 \\
\hline \multirow{7}{*}{ EVA } & 10 & 118 & 166 & & & 215 \\
\hline & 20 & 128 & 180 & 158 & 158 & 213 \\
\hline & 30 & 140 & 183 & & & 225 \\
\hline & 40 & 138 & 190 & & & 215 \\
\hline & 50 & 153 & 160 & 182 & 182 & 193 \\
\hline & 75 & & 169 & & & \\
\hline & 100 & 148 & 168 & 172 & 172 & 198 \\
\hline \multirow{6}{*}{ VVA } & 10 & & 185 & & & \\
\hline & 20 & 145 & 185 & & & 213 \\
\hline & 30 & & 190 & & & \\
\hline & 40 & & 185 & & & \\
\hline & 50 & & 195 & & & \\
\hline & 100 & & 180 & & & \\
\hline \multirow{7}{*}{ SBR } & 10 & & 183 & & & \\
\hline & 20 & 155 & 180 & 180 & 180 & 228 \\
\hline & 30 & & 195 & & & \\
\hline & 40 & & 197 & & & \\
\hline & 50 & & 223 & 223 & 223 & \\
\hline & 75 & & - & & & \\
\hline & 100 & & - & - & - & \\
\hline \multirow{7}{*}{ PAE } & 10 & & 190 & & & \\
\hline & 20 & & 177 & & & \\
\hline & 30 & & 191 & & & \\
\hline & 40 & & 193 & & & \\
\hline & 50 & & 190 & & & \\
\hline & 75 & & 203 & & & \\
\hline & 100 & & 208 & & & \\
\hline
\end{tabular}

${ }^{*}$ Without polymer addition; blank implies no parameter; em dash implies that measurement was impossible.

furnace must be $20^{\circ} \mathrm{C}$ within 20 minutes after heating is commenced, and the average temperature $1 \mathrm{~min}$ after heating is ceased must be less than $20^{\circ} \mathrm{C}$, with less than $30 \%$ weight loss of the specimen.

Moreover, as a mortar contains water and is hence not a uniform material, more than 20 min would be necessary to stabilize the temperature inside the furnace. In this study, the heating time was set as $30 \mathrm{~min}$ from the preliminary experiment. In addition, some specimens (unit polymer content: more than $50 \mathrm{~kg} / \mathrm{m}^{3}$ ) that could undergo ignition or spalling were tested by JIS A 9523 (loose fill thermal insulation materials) in the preliminary experiment [19]. The temperatures of the sample and interior of the furnace were measured using a K-type thermoelectric couple installed at both inside and outside of specimen. Figure 1 shows the setup for the flammability and temperature measurement tests.

\subsection{Mechanical Properties of PCM}

2.2.1. Materials and Composition. The mortar specimen for mechanical property test contained the same materials as shown in Table 1. The experimental parameters and PCM composition were adjusted based on the polymer type, polymer-cement ratio, and hot pressing test, as summarized in Table 3. Four proportions were used for the tests with a fixed water-cement ratio of 50. In this study, the amount of polymer is presented as the weight per unit volume, where $10 \mathrm{~kg} \cdot \mathrm{m}^{-3}$ unit polymer weight in the PCM composition corresponds to a polymer-cement ratio of $2 \%$.

The specimens for the compressive strength test and the elastic modulus test were cylindrical $(100 \mathrm{~mm}$ in diameter and $200 \mathrm{~mm}$ in height) and more than three specimens were prepared for each test. The results presented hereinafter are 

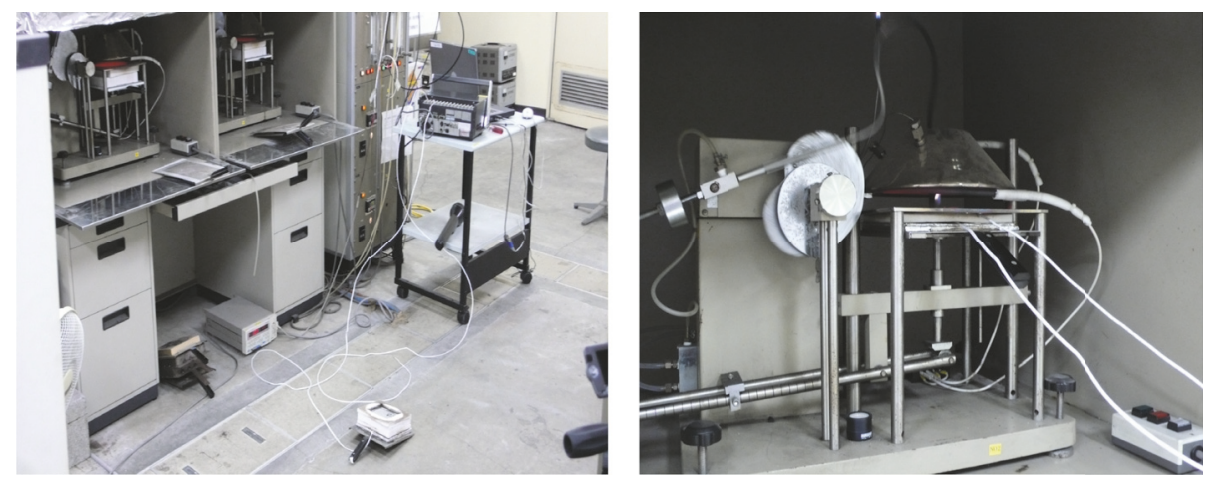

FIGURE 1: Flammability test and temperature measurement test.

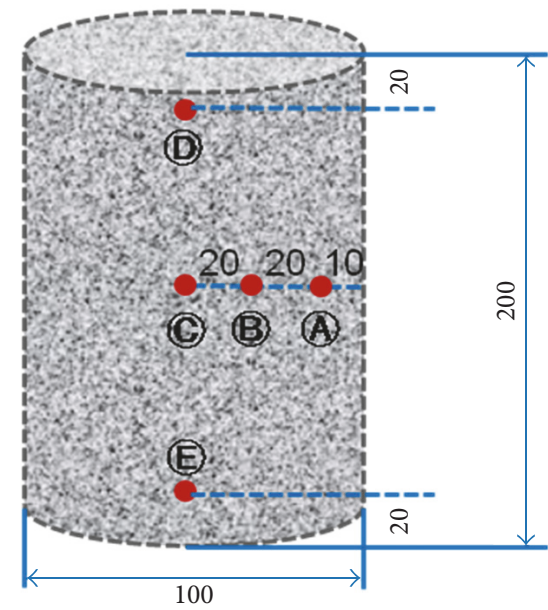

(a) Thermocouple

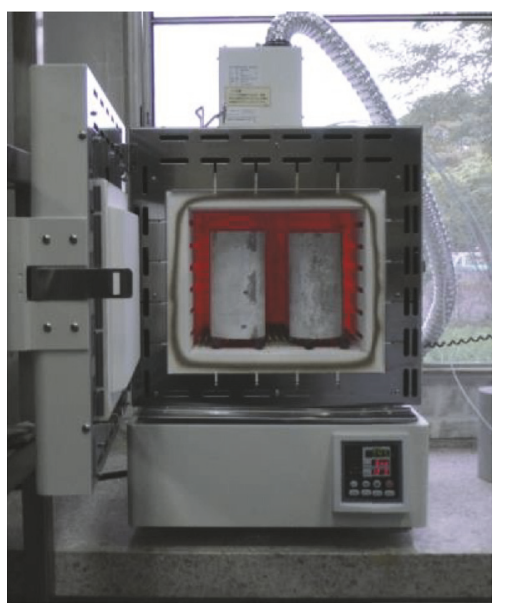

(b) Heating furnace

FIGURE 2: Setup for temperature measurement of PCM.

TABLE 3: Composition of PCM mixtures.

\begin{tabular}{lcccc}
\hline $\begin{array}{l}\text { Type of } \\
\text { polymer }\end{array}$ & $\begin{array}{c}\text { Polymer- } \\
\text { cement ratio } \\
(\%)\end{array}$ & $\begin{array}{c}\text { Water- } \\
\text { cement ratio (\%) }\end{array}$ & $\begin{array}{c}\text { Air content } \\
(\%)\end{array}$ & $\begin{array}{c}\text { Flow } \\
(\mathrm{mm})\end{array}$ \\
\hline None $^{*}$ & 0 & 50 & 4.9 & 171 \\
\hline \multirow{2}{*}{ EVA } & 5 & 50 & 6.2 & 207 \\
& 10 & & 7.6 & 217 \\
& 20 & & 8.7 & 222 \\
\hline \multirow{2}{*}{ VVA } & 5 & 50 & 7.7 & 193 \\
& 10 & & 7.6 & 201 \\
& 20 & & 7.7 & 205 \\
\hline \multirow{3}{*}{ PAE } & 5 & 50 & 6.8 & 194 \\
& 10 & & 8.2 & 203 \\
& 20 & & 9.2 & 224 \\
\hline
\end{tabular}

${ }^{*}$ Without polymer addition.

averages. Each specimen was cured under conditions of $90 \%$ relative humidity at $20^{\circ} \mathrm{C}$ for fourteen days. All specimens were dried under conditions of $60 \%$ relative humidity at $20^{\circ} \mathrm{C}$ for sixty-three days. Finally, all specimens were dried in an oven at $60^{\circ} \mathrm{C}$ for seven days and were kept in a desiccator. Using these procedures, the water absorption rate for each specimen was controlled in range of $1.5 \sim 2.0 \%$.

2.2.2. Test Methods. A hot pressing test method was used to evaluate the mechanical properties of PCM at elevated temperature. As illustrated in Figure 2, five thermocouples were placed into the specimen to measure the temperature changes. Each specimen was placed in the heating furnace for the hot pressing test, as shown in Figure 3. Based on previous data, the rate and amount of heat released from PCM depended on the polymer content regardless of the W/C. In this study, the amount of heat released followed the order $\mathrm{VVA}<\mathrm{EVA}<\mathrm{PAE}<\mathrm{SBR}$. This indicated that $\mathrm{PCM}$ modified with VVA and EVA at polymer contents of less than $75 \mathrm{~kg} \cdot \mathrm{m}^{-3}$ and PCM with PAE at a polymer content of less than $30 \mathrm{~kg} \cdot \mathrm{m}^{-3}$ meet the requirements as incombustible materials.

In the conventional test method at a heating rate of $150^{\circ} \mathrm{C} \cdot \mathrm{h}^{-1}$, the specimen generated spalling after $3 \mathrm{~h}$ of heating with a water absorption rate of $3 \%$. In this study, the water absorption rate was controlled in the range of $1.5 \sim 2.0 \%$, and all specimens were heated at a rate of $100^{\circ} \mathrm{C} \cdot \mathrm{h}^{-1}$. 


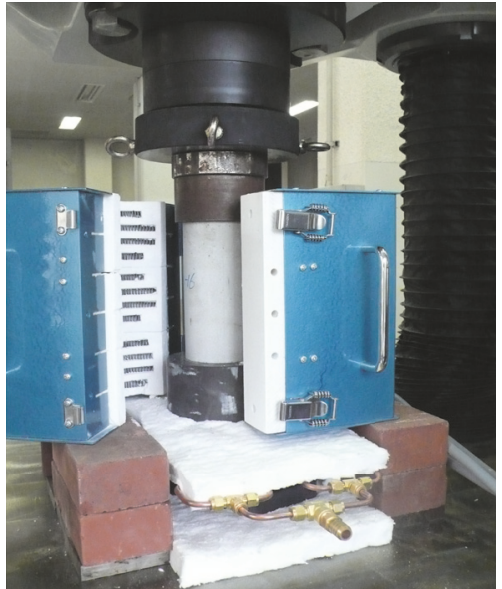

FIGURE 3: Setup for heating compression test.

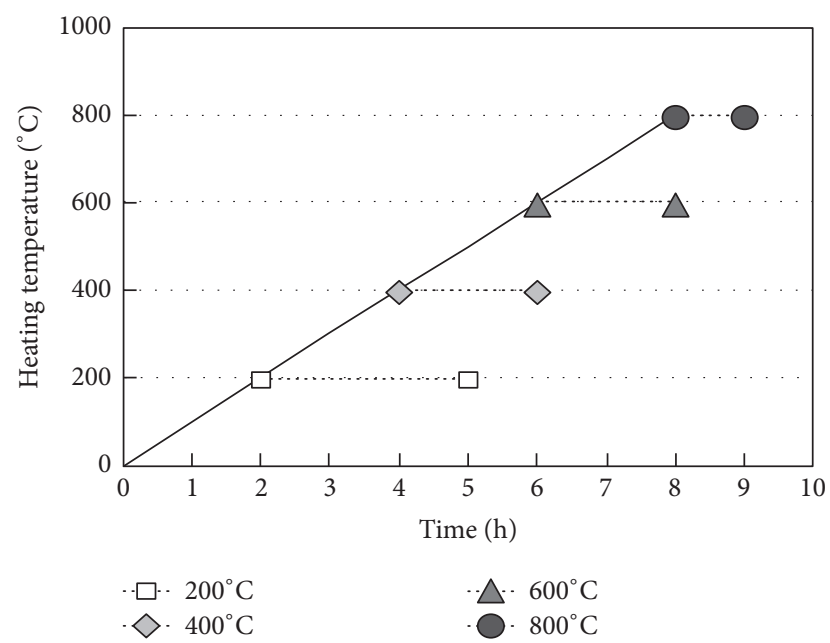

FIGURE 4: Heating program.

The diameter of the test specimen used in the experiment is $100 \mathrm{~mm}$. As shown in Figure 2(a), the thermocouples were embedded in the specimen to check the temperature of the surface, inside, and center of the specimen. When the surface of each specimen reached a predetermined temperature, the heating temperature was maintained until the center of the specimen reached the target temperature. The time for the inside and outside of the PCM to reach the same temperature depends on the heating temperature and time. The heating program used for the furnace is shown in Figure 4. Figure 4 shows the time required to reach the total internal temperature of the specimen in each heating temperature range. In this study, heating temperatures were set to $200^{\circ} \mathrm{C}, 400^{\circ} \mathrm{C}$, $600^{\circ} \mathrm{C}$, and $800^{\circ} \mathrm{C}$. The surface temperature of each specimen reaches $2,4,6$, and 8 hours, respectively. Thereafter, the time at which the center temperature of each specimen reaches the corresponding temperature is $3,2,2$, and 1 hour, respectively. In the case of heating at $200^{\circ} \mathrm{C}$, the time for reaching the inner and outer temperatures to $200^{\circ} \mathrm{C}$ was 5 hours, and for $800^{\circ} \mathrm{C}$,

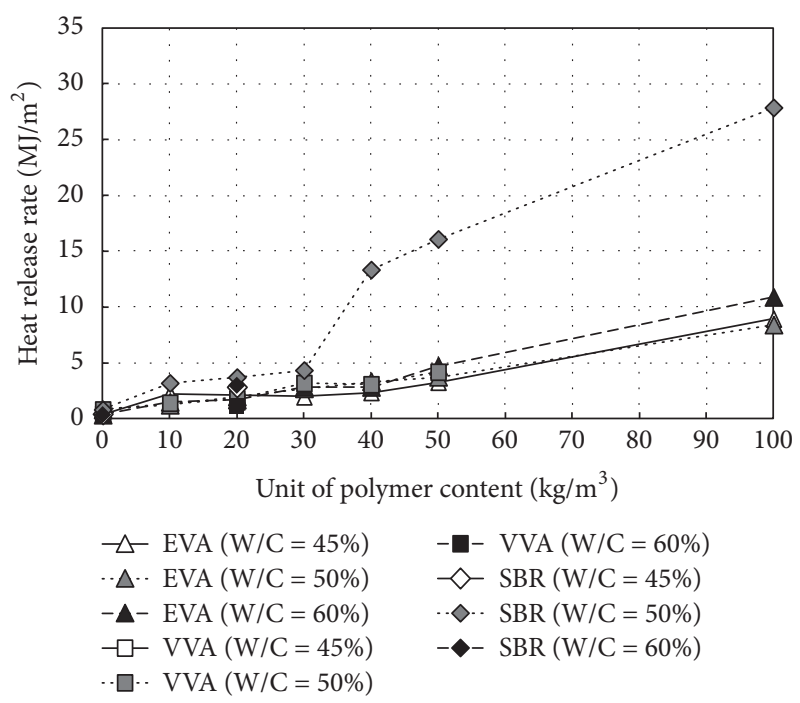

FIGURE 5: Total heat release amount of PCM for 20 min after start of heating.

it took 9 hours for the inner and outer temperatures to reach $800^{\circ} \mathrm{C}$.

As it illustrated in Figure 3, the compressive strength was measured after the temperature at the center of the specimen reached the target temperature.

\section{Results and Analysis}

\subsection{Combustion Properties}

3.1.1. Heat Release Rate Test Results. Specimen fuming was generated in every SBR series and EVA series with $40 \mathrm{~kg} / \mathrm{m}^{3}$ unit polymer content. PCM in the SBR series with more than $40 \mathrm{~kg} / \mathrm{m}^{3}$ polymer content and EVA series containing $100 \mathrm{~kg} / \mathrm{m}^{3}$ polymer content underwent ignition. Spalling was particularly evident in the case of the VVA series specimens with $100 \mathrm{~kg} / \mathrm{m}^{3}$ polymer content. These observations indicate that the fuming, ignition state, and spalling characteristics of the PCMs differ with the polymer type, unit polymer content, and W/C. It was also observed that the specimens without spalling had no cracks or holes, regardless of the presence of the polymer.

Figure 5 illustrates the total heat release amount of the PCM for 20 min after the start of the heating. In case of the EVA and VVA series, the higher the the unit polymer content, the greater the total heat release, regardless of the difference in W/C. In the case of the samples in the SBR series with more than $40 \mathrm{~kg} / \mathrm{m}^{3}$ unit polymer content, the total heat release amount increased with an increase in the polymer content upon ignition. The polymer content and release rate exceeded $40 \mathrm{~kg} / \mathrm{m}^{3}$ and $8 \mathrm{MJ} / \mathrm{m}^{2}$, respectively.

SBR is decomposed into styrene and butadiene-latex at around $200^{\circ} \mathrm{C}$ and is vaporized by pyrolysis at around $360^{\circ} \mathrm{C}$. The temperature at the surface layer of the specimen exceeded the maximum temperature of decomposition and vaporization $5 \mathrm{~min}$ after heating was started. It is thought that 


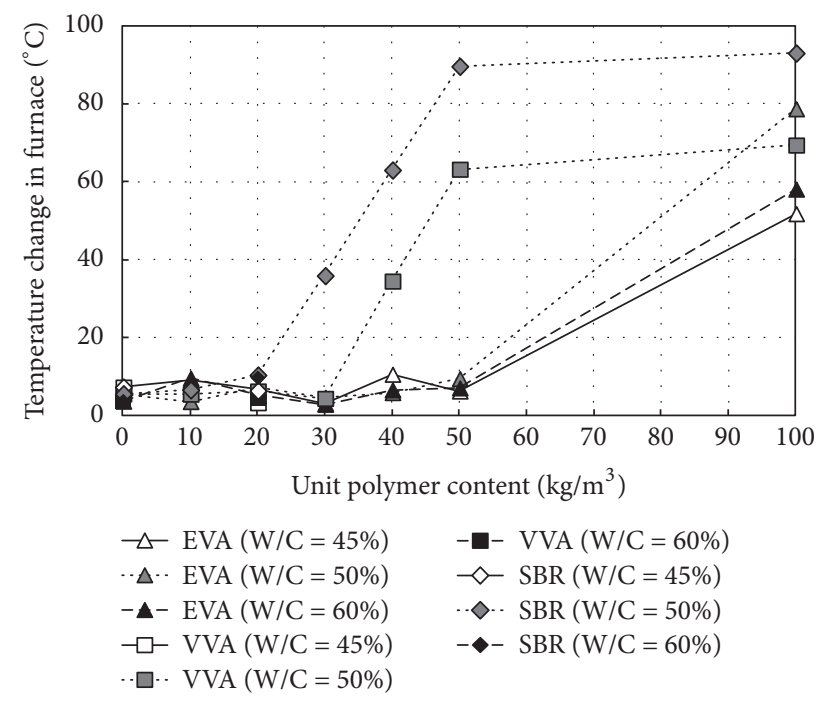

FIGURE 6: Relationship between unit polymer content in PCM and temperature change inside the furnace.

the rapid increase in the heat release amount and heat release rate resulted from the oxygen consumption upon ignition.

3.1.2. Noncombustibility Test Results. Table 4 presents the observation results of the specimens during the test. Spalling occurred between 80 and $180 \mathrm{~s}$; the higher the unit polymer content in the PCM, the faster the spalling. Ignition and smoke generation occurred between 90 and $320 \mathrm{~s}$; again, the higher the unit polymer content in the PCM, the faster the ignition of the sample. Figure 6 also shows the relationship between the polymer content in the PCM and the temperature change inside the furnace.

Temperature change indicates the temperature difference between the maximum temperature inside the furnace $30 \mathrm{~min}$ after the start of heating and the average temperature for $1 \mathrm{~min}$ at the end of heating. The EVA series specimens with a unit polymer content of less than $50 \mathrm{~kg} / \mathrm{m}^{3}$ showed a temperature change of less than $20^{\circ} \mathrm{C}$, while the EVA series with $100 \mathrm{~kg} / \mathrm{m}^{3}$ polymer content showed a temperature change of more than $50^{\circ} \mathrm{C}$. The VVA series with a unit polymer content more than $30 \mathrm{~kg} / \mathrm{m}^{3}$ and the SBR series with a unit polymer content exceeding $20 \mathrm{~kg} / \mathrm{m}^{3}$ showed a temperature change of more than $20^{\circ} \mathrm{C}$. The higher the unit polymer content in the PCM, the greater the temperature change. However, the VVA and SBR series with $100 \mathrm{~kg} / \mathrm{m}^{3}$ unit polymer content showed similar temperature change as the series with a unit polymer content of $50 \mathrm{~kg} / \mathrm{m}^{3}$.

The mass of each PCM series specimen without spalling was also measured after heating end. Figure 7 indicates the relationship between the unit polymer content in the PCM and the mass loss rate after heating. The mass loss rate shows a linear increase with an increase in the unit polymer content.

The mass loss rate of the PCM was less than $30 \%$, regardless of the polymer type, unit polymer content, and $\mathrm{W} / \mathrm{C}$. It is thought that the mass reduction of the PCM was caused by free water in the specimen, some combined

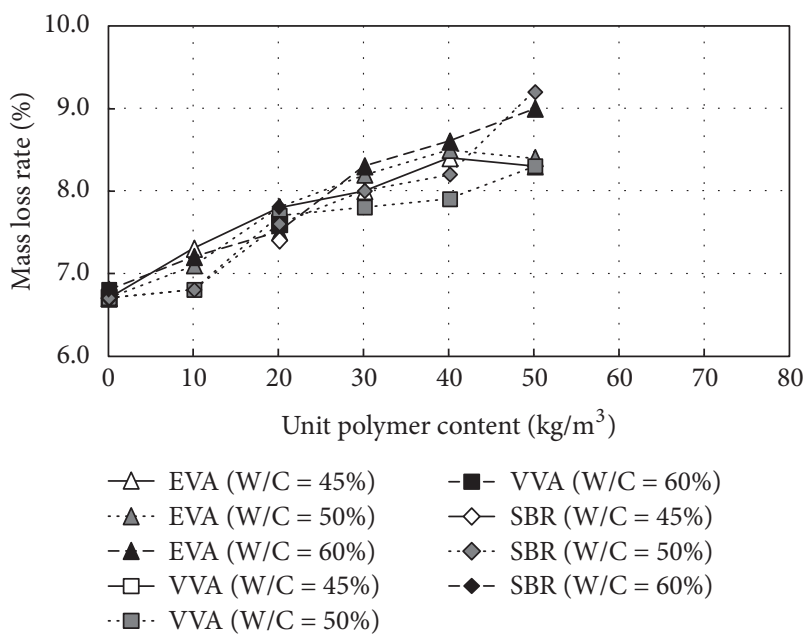

FIGURE 7: Relationship between unit polymer content in PCM and mass loss rate after heating.

water in the cement matrix, and the decomposed polymer. Moreover, it is thought that the increase in mass loss with increasing polymer content was caused by the decomposition of the polymer.

When the polymer content was $10 \mathrm{~kg} / \mathrm{m}^{3}$ and the specimen mass was varied in the range $0.4 \%-0.5 \%$, the mass loss rate of the SBR and VVA series increased with the unit polymer content. Additionally, the results of the noncombustibility test showed that decomposition pattern of the polymer differed between polymer types. In particular, it was thought that the SBR series underwent combustion more readily than the other PCM series, because of the combustion of the polymer.

3.1.3. Evaluation of Combustion Properties Based on PCM Composition and Specimen Thickness. Figure 8 presents the relationship between the unit polymer content in the PCM and the total heat release. Ignition was generated in the case of the PAE series with more than $40 \mathrm{~kg} / \mathrm{m}^{3}$ unit polymer content and specimens with 20,50 , and $100 \mathrm{~kg} / \mathrm{m}^{3}$ unit polymer content in the SBR series. Spalling was generated in the case of the EVA sample with $100 \mathrm{~kg} / \mathrm{m}^{3}$ unit polymer content, while no cracks or holes were found in the other samples of the same series.

As shown in Figure 8, both the PAE series and SBR series show a proportionate relationship to the unit polymer content. It is necessary to consider PCM ignition due to the ignition possibility, especially in the SBR series.

Figure 9 presents the relationship between the thickness of the specimen and the total heat release amount. Ignition occurred in the case of the specimens with $10 \mathrm{~mm}$ thickness, in the SBR and EVA series with $50 \mathrm{~kg} / \mathrm{m}^{3}$ unit polymer content. Spalling was also observed for the samples in the EVA series having 30 and $50 \mathrm{~mm}$ thickness, with $50 \mathrm{~kg} / \mathrm{m}^{3}$ unit polymer content. The thicker the specimen, the lower the total heat release amount because the absolute polymer content increases with the specimen thickness. 


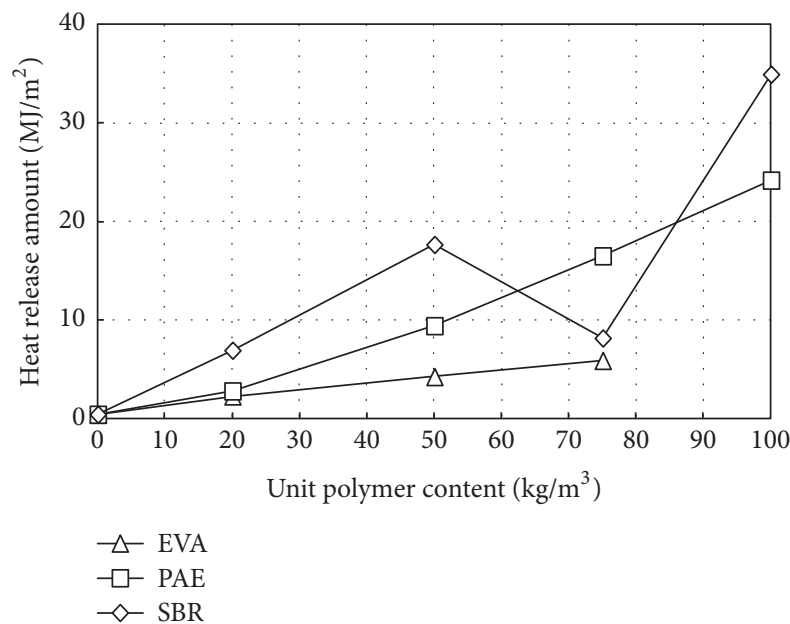

FIGURE 8: Relation between unit polymer content in PCM and total heat release amount.

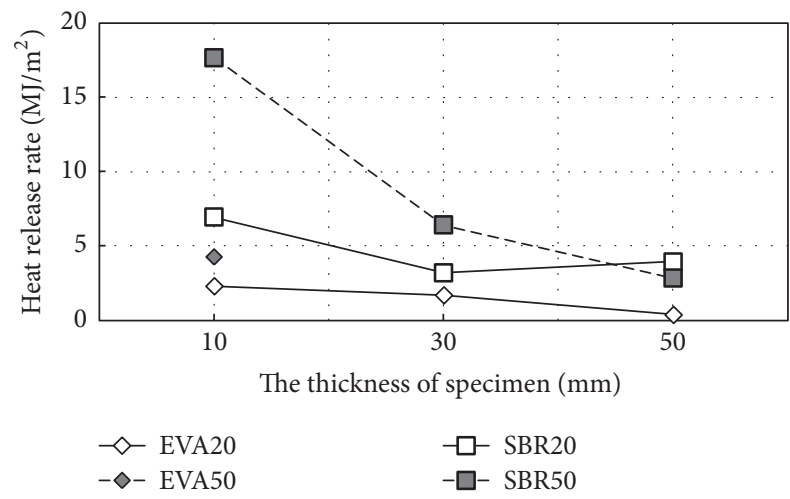

FIGURE 9: Relationship between specimen thickness and total heat release amount.

Figure 10 shows the temperature change for the specimens in the EVA series with $20 \mathrm{~kg} / \mathrm{m}^{3}$ unit polymer content and different thicknesses. For a thickness of $10 \mathrm{~mm}$, the surface temperature increased after $3 \mathrm{~min}$ as compared to that for the other samples; the internal temperature of the specimen increased upon heating, possibly because of the accumulation of heat inside the specimen due to continuous heating. In cases of the specimens with $30 \mathrm{~mm}$ and $50 \mathrm{~mm}$ thickness, the maximum temperature was less than $200^{\circ} \mathrm{C}$.

\subsection{Mechanical Properties}

3.2.1. Mechanical Properties at Room Temperature. The mechanical properties of PCM at room temperature were evaluated based on the polymer type and content. The compressive strength of PCM is presented in Figure 11 and the modulus of elasticity of PCM is shown in Figure 12. The series of EVA- and PAE-modified PCM showed an increase in the compressive strength with increasing polymer content, whereas the VVA-modified PCM series showed little increase. On the other hand, the VVA- and PAE-modified samples showed a decline in the modulus of elasticity with

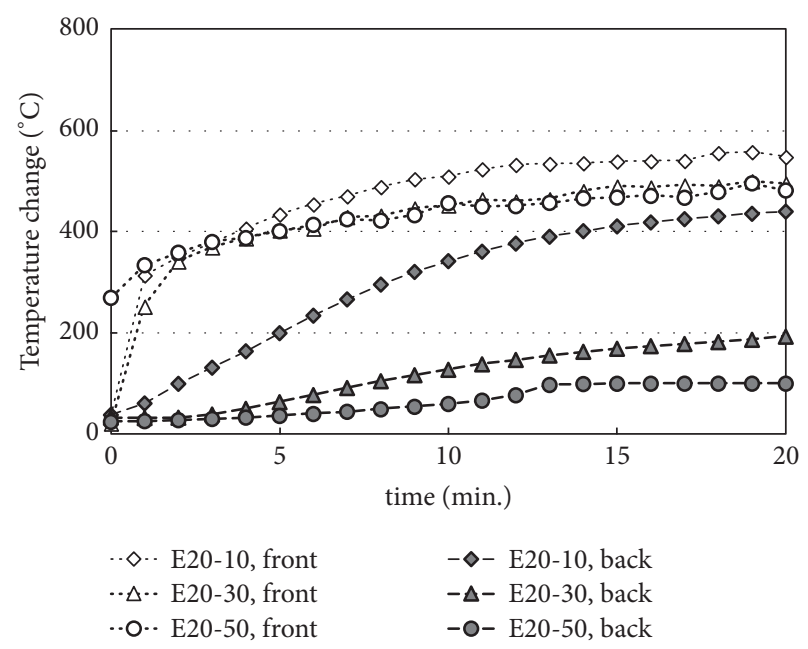

FIGURE 10: Temperature change inside and outside the specimen with specimen thickness.

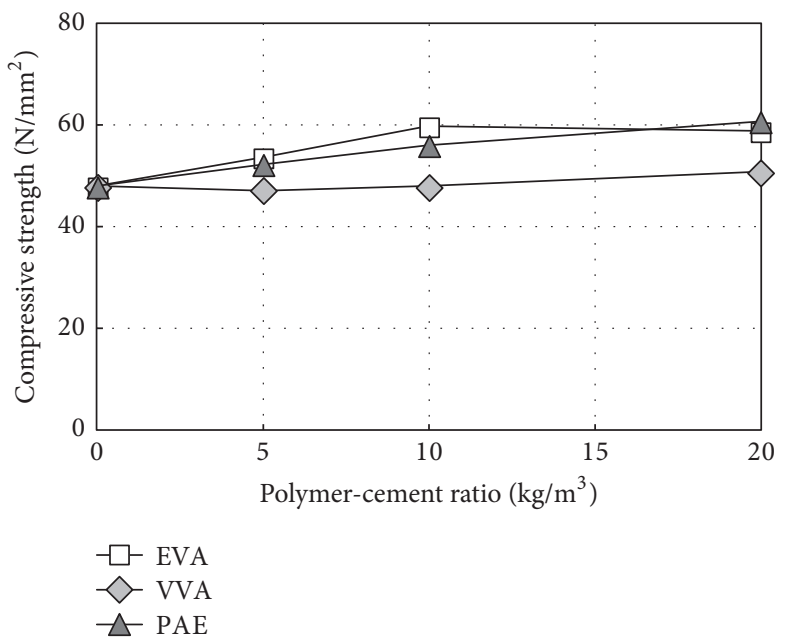

FIGURE 11: Compressive strength of PCM with various polymers at room temperature.

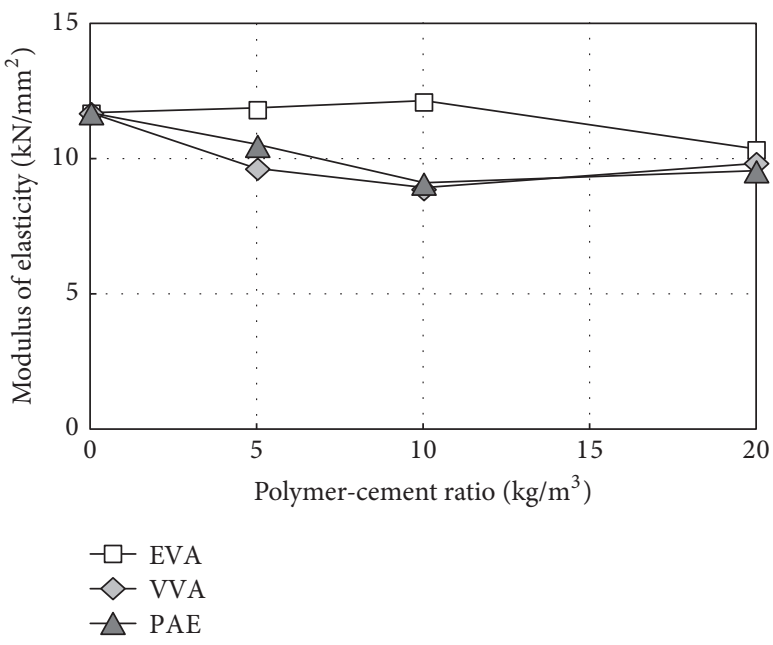

FIgURE 12: Modulus of elasticity of PCM with various polymers at room temperature. 
TABLE 4: Observation of specimens.

\begin{tabular}{|c|c|c|c|c|c|c|c|c|}
\hline \multirow[t]{2}{*}{ State } & \multirow[t]{2}{*}{ Type of polymer } & \multicolumn{7}{|c|}{$\begin{array}{l}\text { Unit polymer content in PCM } \\
\qquad\left(\mathrm{kg} / \mathrm{m}^{3}\right)\end{array}$} \\
\hline & & 0 & 10 & 20 & 30 & 40 & 50 & 100 \\
\hline \multirow{3}{*}{ Spalling } & EVA & & & & & $\triangle$ & $\triangle$ & O \\
\hline & VVA & & & & $\triangle$ & $\triangle$ & & O \\
\hline & SBR & & & & & & $\triangle$ & O \\
\hline \multirow{3}{*}{ Ignition and smoke } & EVA & & & & & & & O \\
\hline & VVA & & & & & & O & O \\
\hline & SBR & & & $\triangle$ & O & O & O & O \\
\hline
\end{tabular}

O: generation at all specimens; $\triangle$ : generation at part of specimens.

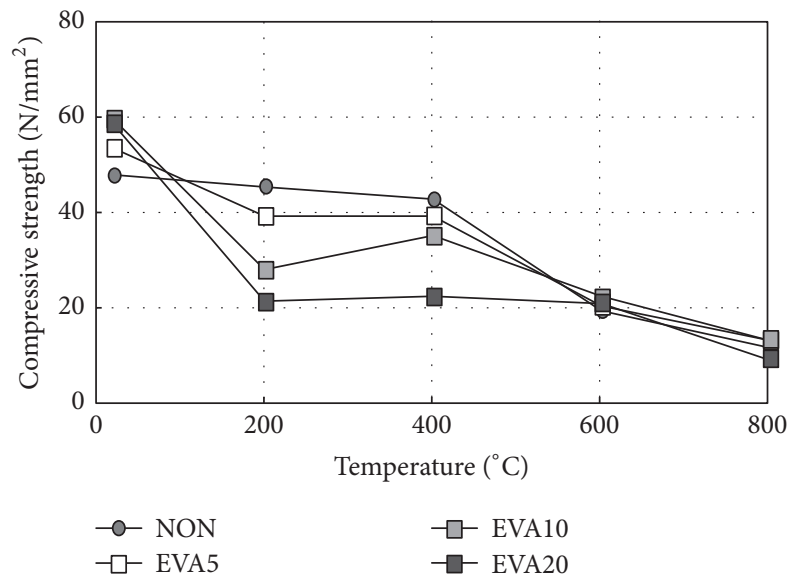

(a) EVA

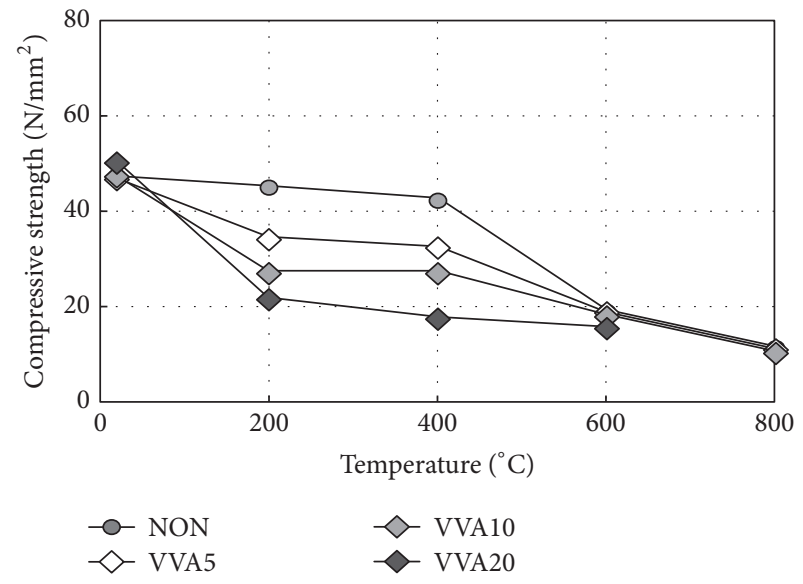

(b) VVA

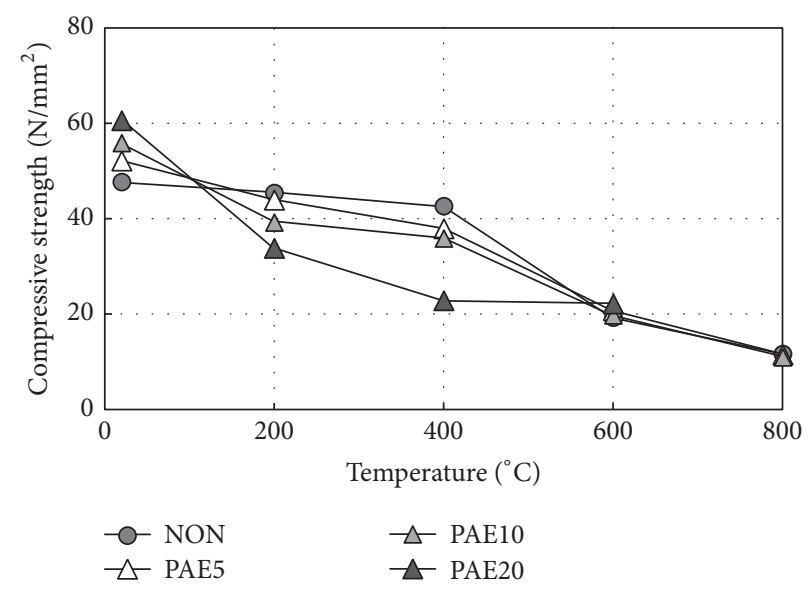

(c) PAE

FIGURE 13: Compressive strength of PCM with various polymers at high temperature.

increasing polymer content. PCM with EVA $10 \%$ and the PAE series showed good mechanical properties.

3.2.2. Mechanical Properties at High Temperature. The mechanical properties of PCM were also evaluated at elevated temperature with variation of the polymer type and content. The compressive strength of the PCM series is shown in Figure 13 and the elastic modulus of PCM is shown in
Figure 14. As shown in Table 4, VVA had a higher spalling risk than the other polymers. The compressive strength test showed that the VVA series had lower strength. According to a previous study, the incombustibility of PCM varies depending on the polymer type and unit polymer content. The compressive strength decreased with increasing polymer content. The PAE series showed excellent fire resistance in the temperature range of $200 \sim 400^{\circ} \mathrm{C}$. On the other hand, the EVA 


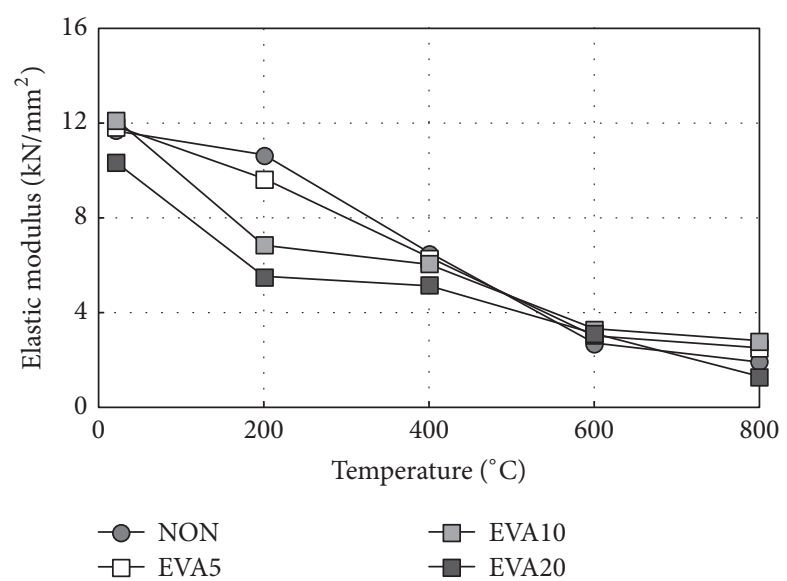

(a) EVA

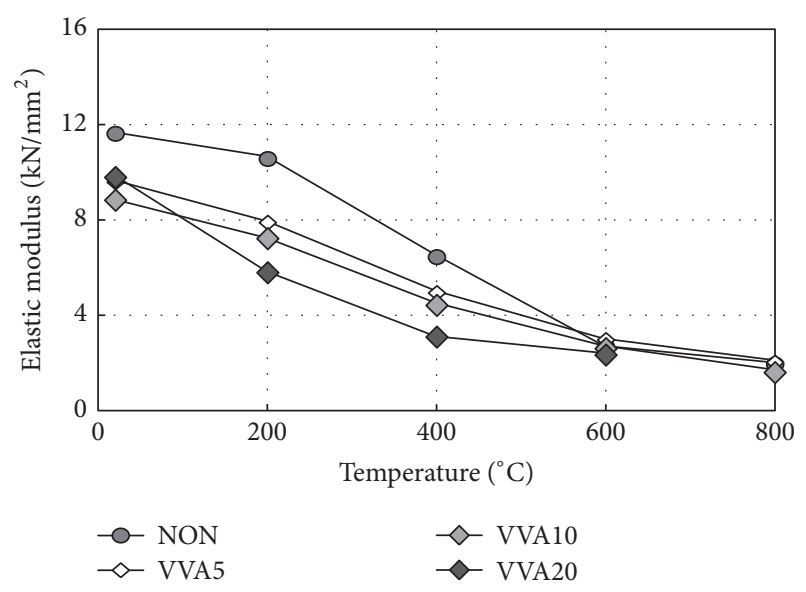

(b) VVA

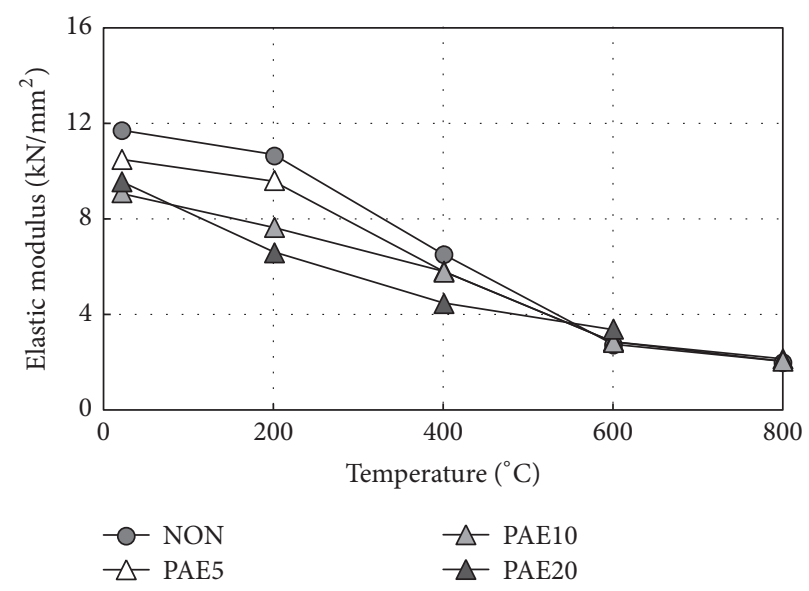

(c) PAE

FIGURE 14: Modulus of elasticity of PCM with various polymers at high temperature.

and VVA series showed a rapid decrease in the compressive strength when the polymer content exceeded 5\%. Most of the specimens showed a decline in the elastic modulus with increasing polymer content, with the exception of the 5\% EVA and 5\% PAE species. PCM with EVA 5\% and the PAE series showed good mechanical properties in temperature range of $200 \sim 400^{\circ} \mathrm{C}$.

\section{Conclusions}

The rate and amount of heat release from a PCM depended on the polymer content, regardless of the W/C. In this study, the heat release amount was found to follow the order $\mathrm{VVA}<$ $\mathrm{EVA}<\mathrm{PAE}<\mathrm{SBR}$.

Specimens in the VVA and EVA series with polymer contents less than $75 \mathrm{~kg} / \mathrm{m}^{3}$, as well as the specimens in the PAE and SBR series with polymer contents less than $30 \mathrm{~kg} / \mathrm{m}^{3}$, met the requirements for an incombustible material. The noncombustibility of the PCM differed depending on the polymer type and unit polymer content. In this study, the incombustibility of the PCM was in the following order: SBR $<$ VVA $<$ EVA.
Given the insufficient experimental data on the fire resistance and safety of PCM, the mechanical properties of PCM at elevated temperature were investigated using three types of polymers as modifiers, namely, EVA, VVA, and PAE.

The test method employed involves spalling risk due to the heating speed and water absorption rate of PCM. This study focused on a water absorption rate of $1.5 \sim 2.0 \%$ and the polymer-cement ratio required to prevent spalling. The hot pressing test demonstrated that PCM with EVA 5\% and the PAE series showed good mechanical properties in the temperature range of $200 \sim 400^{\circ} \mathrm{C}$.

\section{Conflicts of Interest}

The authors declare that there are no conflicts of interest regarding the publication of this paper.

\section{Acknowledgments}

This research was supported by the Fire Fighting Safety \& 119 Rescue Technology Research and Development Program 
funded by the Ministry of Public Safety and Security (NEMANext Generation-2014-58).

\section{References}

[1] Y. Ohama, "Polymer-based admixtures," Cement and Concrete Composites, vol. 20, no. 2-3, pp. 189-212, 1998.

[2] ACI Committee 548, State-Of-The-Art Report on Polymer Modified Concrete (548.3R-95), Farmington Hills, MI, USA, American Concrete Institute.

[3] Y. Ohama, Handbook of Polymer-Modified Concrete and Mortars, Properties and Process Technology, Noyes Publications, Park Ridge, NJ, USA, 1995.

[4] K. P. Grosskurth and A. Konietzko, "Structure and mechanical behaviour of polymer modified cement concrete," in Proceeding of 5th International Congress on Polymers in Concrete, pp. 171174, 1987.

[5] M. Wang, R. Wang, H. Yao et al., "Research on the mechanism of polymer latex modified cement," Construction and Building Materials, vol. 111, pp. 710-718, 2016.

[6] L. K. Aggarwal, P. C. Thapliyal, and S. R. Karade, "Properties of polymer-modified mortars using epoxy and acrylic emulsions," Construction and Building Materials, vol. 21, no. 2, pp. 379-383, 2007.

[7] D. Park, J. Ahn, S. Oh, H. Song, and T. Noguchi, "Drying effect of polymer-modified cement for patch-repaired mortar on constraint stress," Construction and Building Materials, vol. 23, no. 1, pp. 434-447, 2009.

[8] D. Park, S. Park, Y. Seo, and T. Noguchi, "Water absorption and constraint stress analysis of polymer-modified cement mortar used as a patch repair material," Construction and Building Materials, vol. 28, no. 1, pp. 819-830, 2012.

[9] J. Mirza, M. S. Mirza, and R. Lapointe, "Laboratory and field performance of polymer-modified cement-based repair mortars in cold climates," Construction and Building Materials, vol. 16, no. 6, pp. 365-374, 2002.

[10] A. Yahia, "Shear-thickening behavior of high-performance cement grouts - Influencing mix-design parameters," Cement and Concrete Research, vol. 41, no. 3, pp. 230-235, 2011.

[11] C. A. Anagnostopoulos, G. Sapidis, and E. Papastergiadis, "Fundamental properties of epoxy resin-modified cement grouts," Construction and Building Materials, vol. 125, pp. 184-195, 2016.

[12] J.-P. Won, S.-W. Choi, C.-G. Park, and C.-I. Jang, "High strength polymer-modified repair cementitious composite for fire protection," Polymers and Polymer Composites, vol. 15, no. 5, pp. 379-388, 2007.

[13] J.-P. Won, H.-B. Kang, S.-J. Lee, and J.-W. Kang, "Eco-friendly fireproof high-strength polymer cementitious composites," Construction and Building Materials, vol. 30, pp. 406-412, 2012.

[14] Y. Qiao, J. K. Deliwala, S. S. Chakravarthula, and X. Kong, "High-temperature tensile properties of a polymer intercalated/exfoliated cement," Materials Letters, vol. 59, no. 28, pp. 3616-3619, 2005.

[15] H. Hamasaki, H. J. Kim, and T. Noguchi, "Study on heat release properties of polymer-modified cement mortar," in Proceedings of the Part 1 Effect of the Unit Polymer Weight and Mixed Design, pp. 435-436, 2009.

[16] H. J Kim, H. hamasaki, and T. Noguchi, "Study on heat release properties of polymer-modified cement mortar," in Proceedings of the Part 2 Effect on the Thickness of Specimen on Annual Conference of Architectural Institute of Japan, pp. 437-438, 2009.
[17] ISO, ISO 5660-1:2015 Reaction-to-fire tests - Heat release, smoke production and mass loss rate - Part 1: Heat release rate (cone calorimeter method) and smoke production rate (dynamic measurement), Geneva. Switzerland: International Organization for Standardization; 2015.

[18] ISO, ISO 1182: Reaction to fire tests for building products - Non-combustibility test, Geneva. Switzerland: International Organization for Standardization; 2010.

[19] JIS, JIS A 9523, Loose fill thermal insulation materials, Japanese Standards Association; 2016. 

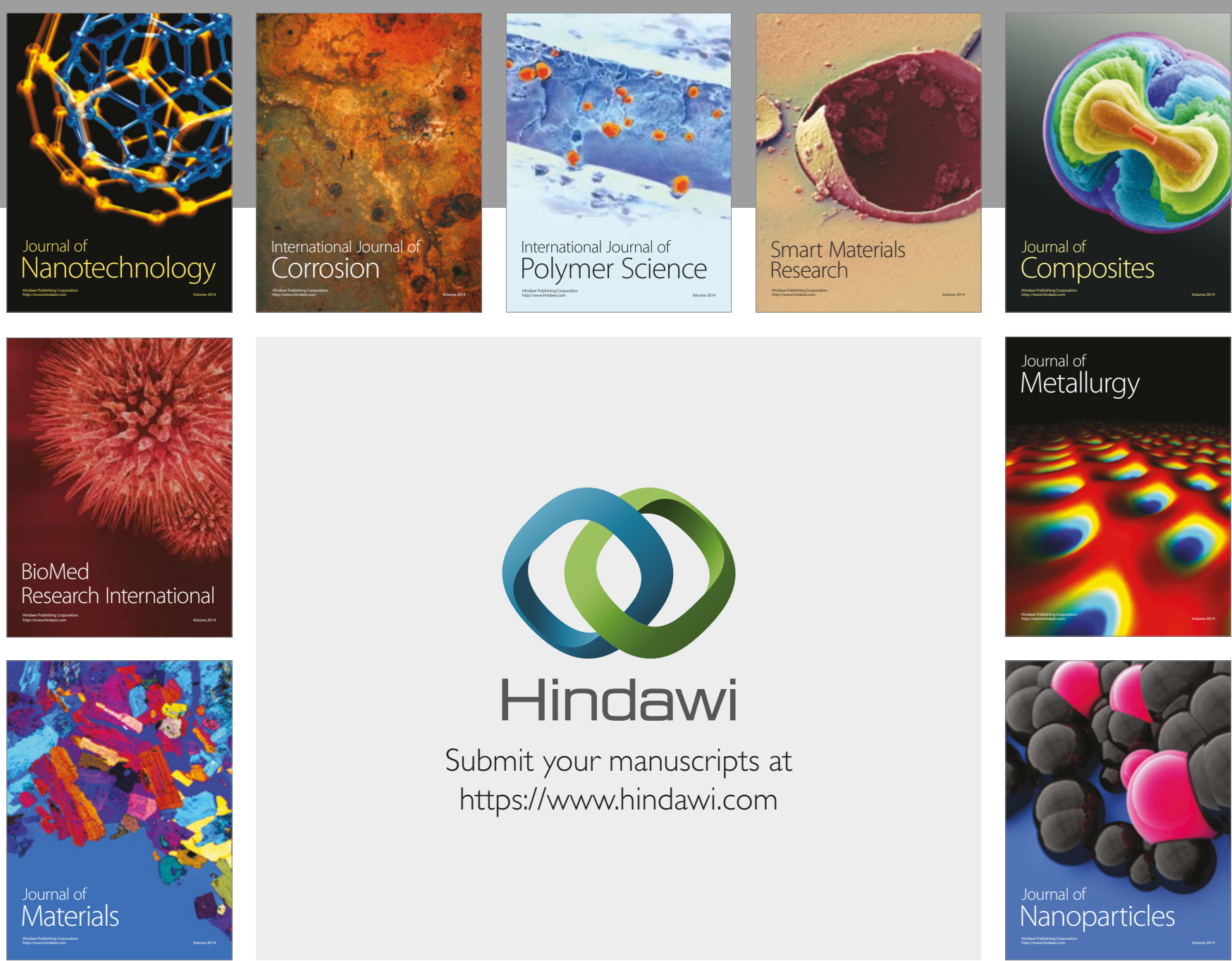

\section{Hindawi}

Submit your manuscripts at

https://www.hindawi.com
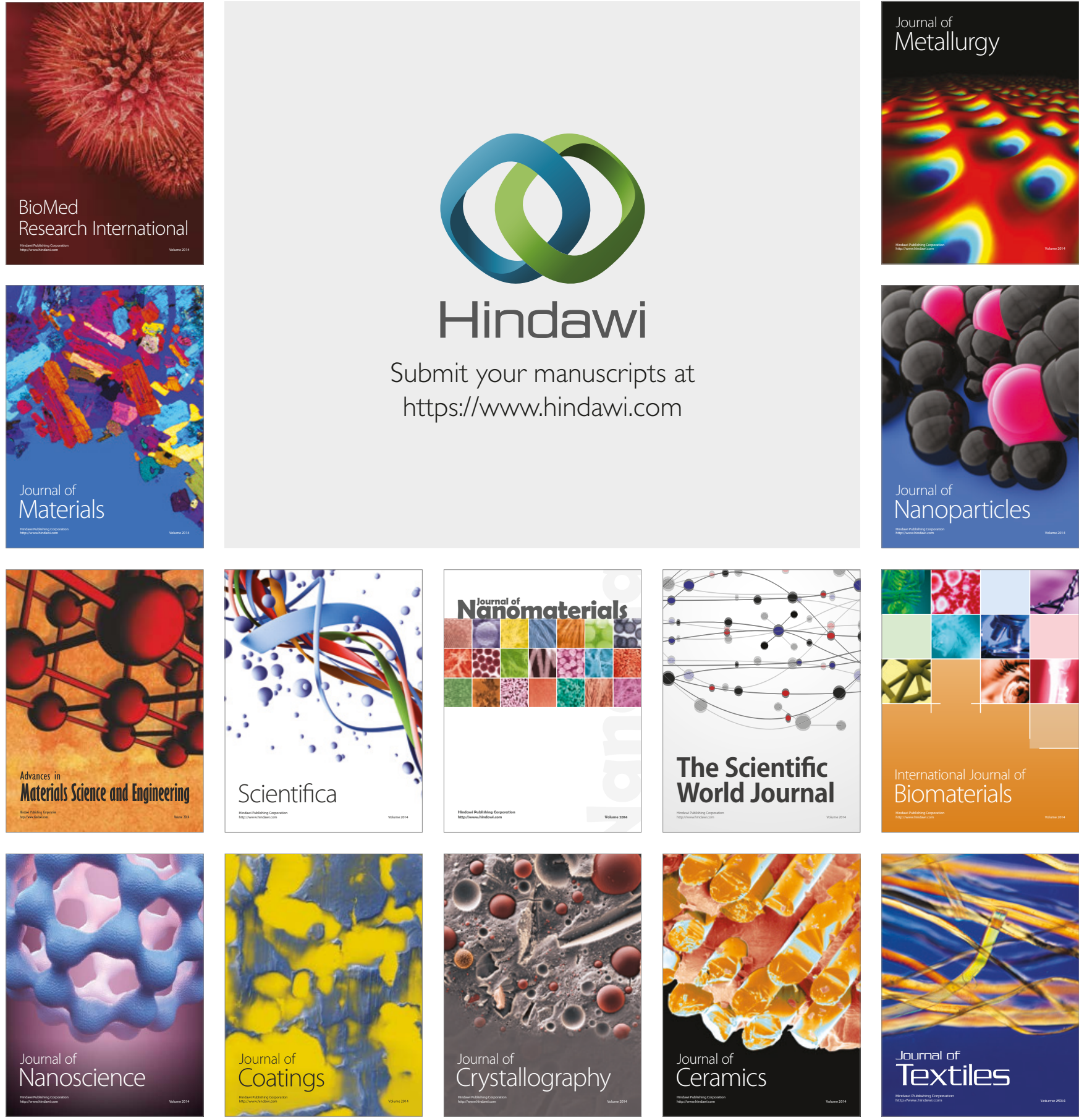

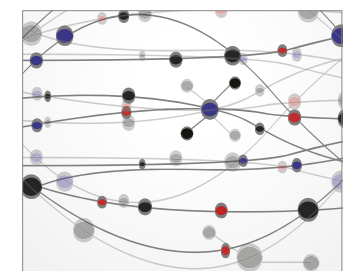

The Scientific World Journal
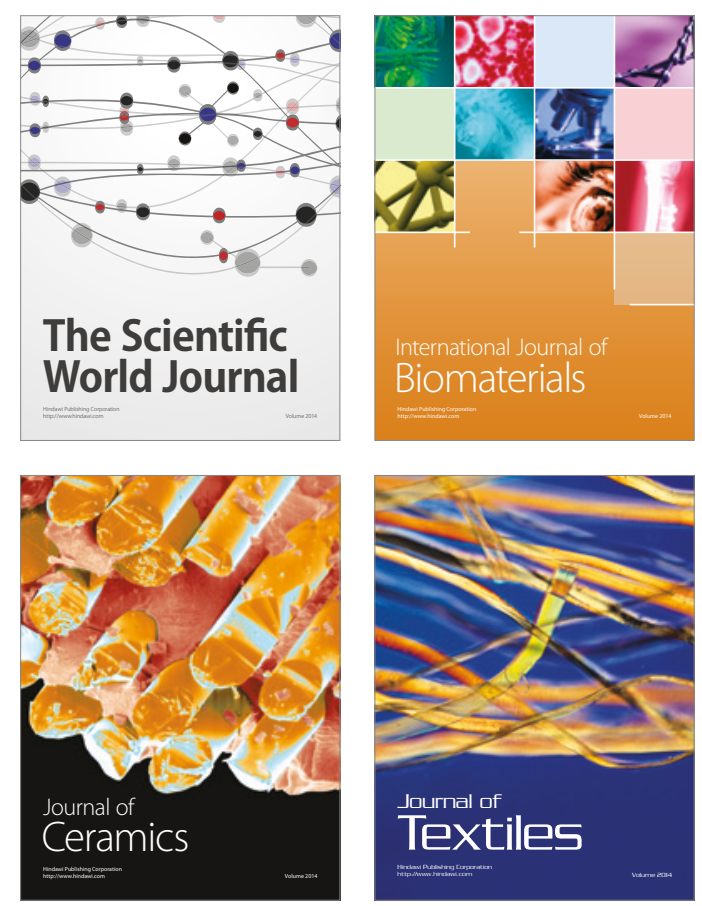